\title{
Correction to: Concept design of an illicit material detection system
}

\author{
Ali M. Al-Bahi ${ }^{1} \cdot$ Abdelfattah Y. A. Soliman $^{1} \cdot$ Mohamed H. M. Hassan ${ }^{1} \cdot$ Nader M. A. Mohamed $^{2}$
}

Published online: 27 June 2018

(C) Akadémiai Kiadó, Budapest, Hungary 2018

\section{Correction to: J Radioanal Nucl Chem (2014) 299:351-356} https://doi.org/10.1007/s10967-013-2723-4

In the original publication of the article, the Acknowledgement section was missed. The complete Acknowledgement is given in this correction.
Acknowledgements This project was funded by the National Plan for Science, Technology and Innovation (MAARIFAH) - King Abdulaziz City for Science and Technology-the Kingdom of Saudi Arabia-Award Number 10-MAT1267-03. The authors also acknowledge with thanks Science and Technology Unit, King Abdulaziz University for technical support.

The original article can be found online at https://doi.org/10.1007/s10967-013-2723-4.

Ali M. Al-Bahi

abahi@kau.edu.sa

Nader M. A. Mohamed

mnader73@yahoo.com

1 Faculty of Engineering, King AbdulAziz University, Jeddah, Saudi Arabia

2 Atomic Energy Authority, ETRR-2, Cairo, Egypt 